\title{
Clinical Outcomes of Dialysis Patients Treated with Drug-Eluting Stent for Left Main Distal Bifurcation Lesions
}

\author{
Yusuke Watanabe ${ }^{a, b}$ Satoru Mitomob Ozan M. Demir ${ }^{a}$ Kuan-Liang Liu ${ }^{c}$ \\ Ying-Chang Tung $^{d}$ Alaide Chieffo $^{a}$ Matteo Montorfano ${ }^{a}$ Chi-Jen Chang $^{d}$ \\ Sunao Nakamurab Antonio Colombo ${ }^{\mathrm{e}}$

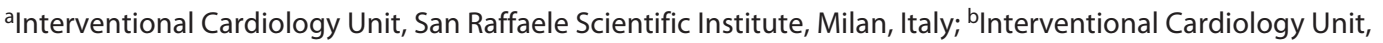 \\ New Tokyo Hospital, Chiba, Japan; 'Department of Cardiology, Landseed International Hospital, Taoyuan, Taiwan; \\ dDivision of Cardiology, Department of Internal Medicine, Chang Gung Memorial Hospital, Chang Gung University \\ College of Medicine, Taoyuan, Taiwan; 'Interventional Cardiology Unit, EMO-GVM, Centro Cuore Columbus, Milan, \\ and Villa Maria Cecilia Hospital GVM, Lugo, Italy
}

\section{Keywords}

Stable angina - Percutaneous coronary intervention .

Dialysis · Left main · Bifurcations

\begin{abstract}
Aims: We assessed clinical outcomes after percutaneous coronary intervention $(\mathrm{PCl})$ for unprotected left main coronary artery (ULMCA) distal bifurcation lesions using drug-eluting stents (DES) in hemodialysis (HD) patients compared to nonHD patients. Methods and Results: We identified 1,858 consecutive patients who underwent PCI for ULMCA distal bifurcation lesions at 4 high-volume centers in Japan, Italy, and Taiwan between January 2005 and December 2015. Of them, 1,416 patients were treated with DES including $113 \mathrm{HD}$ patients and 1,303 non-HD patients. The primary end point was target lesion failure (TLF) defined as a composite of cardiac death, target lesion revascularization (TLR), and myocardial infarction. HD patients were more likely to be younger and have diabetes mellitus, dyslipidemia, peripheral artery disease, lower ejection fraction, and higher EuroSCORE. TLF rate at 3 years was significantly higher in HD group than in non-
\end{abstract}

karger@karger.com

(C) 2021 S. Karger AG, Basel

www.karger.com/crm

Karger"
HD group (adjusted hazard ratio [HR] 2.43 [1.75-3.38], $p<$ 0.001 ). Cardiac mortality and TLR rate were also significantly higher in HD group than in non-HD group (adjusted HR 3.85 [2.34-6.34], $p<0.001$, and HR 2.10 [1.41-3.14], $p<0.001$, respectively). Conclusions: HD was strongly associated with adverse cardiac events after PCI for ULMCA distal bifurcation lesions with DES.

(C) 2021 S. Karger AG, Basel

\section{Introduction}

Drug-eluting stents (DES) have dramatically improved clinical outcomes following percutaneous coronary intervention (PCI), especially target lesion revascularization (TLR) rates, compared with bare-metal stents [1]. Consequently, PCI for unprotected left main coronary artery (ULMCA) lesions has been widely performed, especially

Yusuke Watanabe

Interventional Cardiology Unit, New Tokyo Hospital

Chiba, 1271 Wanagaya

Matsudo 270-2232 (Japan)

yusukeltcr@yahoo.co.jp

Antonio Colombo

Maria Cecilia Hospital, GVM, Care \& Research

Cotignola (RA) and EMO-GVM, Centro Cuore Columbus

Via Michelangelo Buonarroti 48 IT-20145, Milan (Italy)

acolombo50@me.com 
in patients with a low to intermediate SYNTAX score [2, 3]. In recent years, the introduction of current generation DES (cDES) further improved clinical outcomes after PCI compared to early generation DES [4].

On the contrary, CKD is a well-recognized independent risk factor for the development of coronary artery disease [5] and is associated with poorer clinical outcomes after successful PCI compared to those in the patients with normal renal function [6]. In addition, CKD has various severities, the most severe being ESRD requiring hemodialysis (HD). Previous studies have reported worse clinical outcomes in HD patients compared to non-HD patients $[7,8]$. However, clinical outcome data remain extremely scarce in $\mathrm{HD}$ patients undergoing PCI for ULMCA lesions because patients on HD are often excluded from randomized controlled trials [9]. Therefore, we assessed clinical outcomes after PCI for ULMCA distal bifurcation lesions using DES in HD patients compared to non-HD patients.

\section{Methods}

\section{Study Population}

Study flow chart is shown in Figure 1. We identified 1,858 consecutive patients who underwent PCI for ULMCA distal bifurcation lesions at New Tokyo Hospital (Chiba, Japan), San Raffaele Scientific Institute and EMO-GVM Centro Cuore Columbus (Milan, Italy), and Landseed International Hospital and Linkou Chang Gung Memorial Hospital (Taoyuan, Taiwan) between January 2005 and December 2015. Of 1,858 patients, 1,422 patients were treated with DES. Among them, there were $113 \mathrm{HD}$ patients (HD group), and 1,303 non-HD patients (non-HD group). In this study, all dialysis patients underwent HD. Patients on peritoneal dialysis were not included. Additionally, acute coronary syndrome was excluded from this study. All patients were performed elective PCI for stable angina. The relevant review boards in each institute approved the study protocol.

ULMCA disease was defined as a stenosis of at least $50 \%$ that involved the ostium, body, or distal segment of the left main coronary artery or within the proximal $5 \mathrm{~mm}$ of the left anterior descending coronary artery or left circumflex coronary artery. ULMCA lesions were divided into the following 2 groups: (1) ostium and body (non-bifurcation lesions) and (2) distal bifurcation lesions. Because most of HD patients had distal bifurcation lesions (only $3 \mathrm{HD}$ patients [3.3\%] had non bifurcation lesions), this study included only distal bifurcation lesions. Bifurcation lesions were classified according to the Medina classification [10] by 2 independent physicians. A true bifurcation lesion was defined as Medina class 1-1-1, 1-0-1, and 0-1-1.

\section{Stent Implantation}

The stents used in the present study were sirolimus-eluting stents (SES) (Cypher family, Cordis Corporation, Johnson \& Johnson, Warren, NJ, USA, and Ultimaster; Terumo Corporation, Tokyo, Japan), paclitaxel-eluting stent (Taxus family, Boston Scien-

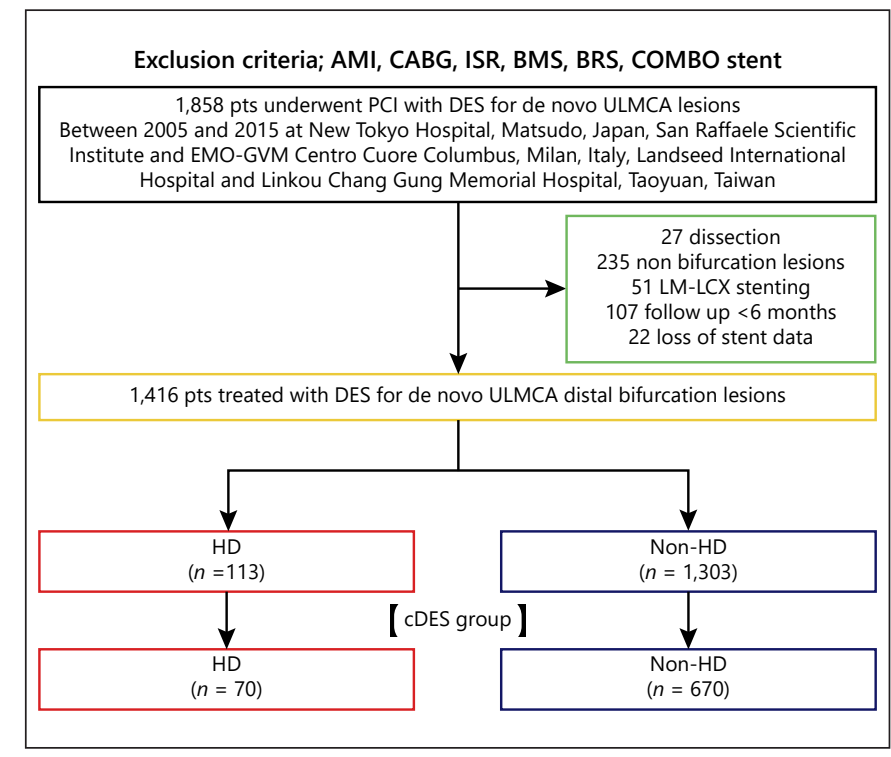

Fig. 1. Study flow chart. AMI, acute myocardial infarction; CABG, coronary artery bypass graft surgery; ISR, in-stent restenosis; BMS, bare-metal stent; BRS, bioresorbable vascular scaffold; PCI, percutaneous coronary intervention; DES, drug-eluting stent; ULMCA, unprotected left main coronary artery; LM, left main; LCX, left circumflex artery; HD, hemodialysis; cDES, current generation drug-eluting stent.

tific, Natick, MA, USA), zotarolimus-eluting stents (Endeavor family and Resolute family, Medtronic, Santa Rosa, CA, USA), everolimus-eluting stents (Xience family [Abbott Vascular, Santa Clara, CA, USA], Promus family and Synergy [Boston Scientific, Natick, MA, USA]), and biolimus-eluting stent (Nobori, Terumo Corporation, Tokyo, Japan). In this study, cDES included Ultimaster, Resolute family, Xience family, Promus family, Synergy, and Nobori.

Single-stent strategy (SSS) was defined as the use of a single stent, regardless of the lesion type. A double-stent strategy (DSS) was defined as the use of 2 stents, regardless of the technique used. This study included the provisional strategies with DSS, such as the crush, mini-crush, culotte, $\mathrm{T}$ and protrusion, $\mathrm{T}$-stenting, $\mathrm{V}$-stenting, and kissing stenting. The main strategy of stenting was decided at the operator's discretion. Kissing balloon inflation and proximal optimization technique (POT) after stent implantation were also dependent on the operator's discretion.

\section{Medications}

In patients who were not receiving aspirin, low-dose aspirin ( 100 or $200 \mathrm{mg} /$ day) was administered before the procedure. All the patients received a loading dose of $300 \mathrm{mg}$ of clopidogrel or 20 $\mathrm{mg}$ of prasugrel unless they were on a long-term treatment. In the catheterization laboratory, heparin was administered to maintain an activated clotting time of $\geq 250$ or $200-250$ s. After PCI, a lifelong administration of aspirin (100 $\mathrm{mg} /$ day) was prescribed, and clopidogrel (75 mg/day) or prasugrel (3.75 mg/day in Japan or 5.0 $\mathrm{mg}$ /day in Taiwan and Italy) was prescribed for at least 12 months, regardless of DES type. 
Table 1. Baseline clinical characteristics

\begin{tabular}{|c|c|c|c|}
\hline & $\begin{array}{l}\mathrm{HD} \\
(n=113)\end{array}$ & $\begin{array}{l}\text { Non-HD } \\
(n=1,303)\end{array}$ & $p$ value \\
\hline Age & $67.5 \pm 9.7$ & $69.7 \pm 9.7$ & 0.02 \\
\hline Male gender, $n(\%)$ & $83(73.5)$ & $1,035(79.4)$ & 0.15 \\
\hline BMI & $22.5 \pm 3.4$ & $23.7 \pm 3.7$ & 0.006 \\
\hline Albumen & $3.6 \pm 0.5$ & $3.8 \pm 0.5$ & 0.001 \\
\hline Previous MI, $n(\%)$ & $30(26.5)$ & $467(35.8)$ & 0.05 \\
\hline Previous stroke, $n(\%)$ & $14(12.4)$ & $91(7.0)$ & 0.06 \\
\hline $\mathrm{DM}, n(\%)$ & $81(71.7)$ & $513(39.4)$ & $<0.001$ \\
\hline Insulin DM, $n(\%)$ & $34(30.1)$ & $95(7.3)$ & $<0.001$ \\
\hline HbAlc, \% & $5.9 \pm 1.0$ & $6.5 \pm 1.2$ & 0.02 \\
\hline $\mathrm{HT}, n(\%)$ & $98(86.7)$ & $1,023(78.5)$ & 0.04 \\
\hline $\mathrm{DL}, n(\%)$ & $59(52.2)$ & $906(69.5)$ & $<0.001$ \\
\hline Total cholesterol, mg/dL & $174.2 \pm 42.0$ & $170.7 \pm 36.5$ & 0.55 \\
\hline HDL cholesterol, mg/dL & $42.0 \pm 11.5$ & $44.4 \pm 11.8$ & 0.11 \\
\hline LDL cholesterol, mg/dL & $92.9 \pm 32.4$ & $101.3 \pm 32.2$ & 0.10 \\
\hline Triglyceride, mg/dL & $127.5 \pm 96.3$ & $134.7 \pm 80.3$ & 0.48 \\
\hline CKD $(\mathrm{e}-\mathrm{GFR}<60), n(\%)$ & $113(100.0)$ & $553(42.4)$ & $<0.001$ \\
\hline $\mathrm{PAD}, n(\%)$ & $62(54.9)$ & $157(12.0)$ & $<0.001$ \\
\hline $\mathrm{EF}, \%$ & $50.5 \pm 13.0$ & $56.1 \pm 10.4$ & $<0.001$ \\
\hline EuroSCORE logistic & $9.31 \pm 9.1$ & $4.37 \pm 5.0$ & $<0.001$ \\
\hline \multicolumn{4}{|l|}{ Smoking status } \\
\hline Never & $23(37.7)$ & $210(33.8)$ & 0.75 \\
\hline Past & $31(50.8)$ & $323(51.9)$ & \\
\hline Current & $7(11.5)$ & $89(14.3)$ & \\
\hline \multicolumn{4}{|l|}{ Medication } \\
\hline Aspirin & $75(98.7)$ & $708(99.6)$ & 0.33 \\
\hline Ticlopidine & $7(9.2)$ & $65(9.2)$ & 1.00 \\
\hline Clopidogrel & $63(82.9)$ & $616(86.9)$ & 0.38 \\
\hline Prasugrel & $4(5.3)$ & $25(3.5)$ & 0.52 \\
\hline Warfarin & $6(7.9)$ & $68(9.6)$ & 0.84 \\
\hline Statin & $25(32.9)$ & $239(33.7)$ & 1.00 \\
\hline ARB/ACE-I & $21(27.6)$ & $195(27.5)$ & 1.00 \\
\hline$\beta$-blocker & $18(23.7)$ & $172(24.3)$ & 1.00 \\
\hline $\mathrm{CCB}$ & $28(36.8)$ & $309(43.6)$ & 0.28 \\
\hline
\end{tabular}

Data are presented as percentages and absolute numbers or means \pm standard deviation, unless otherwise specified. HD, hemodialysis; MI, myocardial infarction; DM, diabetes mellitus; HT, hypertension; DL, dyslipidemia; HDL, high-density lipoprotein; LDL, low-density lipoprotein; e-GFR, estimated glomerular filtration rate; $\mathrm{PAD}$, peripheral arterial disease; $\mathrm{EF}$, ejection fraction; $\mathrm{ARB}$, angiotensin II receptor blocker; ACE-I, angiotensin-converting enzyme inhibitor; $\mathrm{CCB}$, calcium channel blocker.

\section{Study End points}

The primary end point was target lesion failure (TLF). TLF was defined as a composite of cardiac death, TLR, and myocardial infarction (MI) at 3 years after index PCI. The individual components of TLF were also evaluated. Death was considered as cardiac in origin unless obvious noncardiac causes were identified. The TLR was defined as a repeat revascularization by PCI or coronary artery bypass graft surgery of the target lesion. Periprocedural MI and stent thrombosis were defined according to the Ac-
Table 2. Lesion and procedural characteristics

\begin{tabular}{|c|c|c|c|}
\hline Patients, $n$ & $\begin{array}{l}\mathrm{HD} \\
(n=113)\end{array}$ & $\begin{array}{l}\text { Non-HD } \\
(n=1,303)\end{array}$ & $p$ value \\
\hline \multicolumn{4}{|l|}{ True bifurcation } \\
\hline (Medina 111,101 , and 011 ) & $71(63.4)$ & $742(56.9)$ & 0.20 \\
\hline $3 \mathrm{VD}, n(\%)$ & $70(61.9)$ & $636(49.0)$ & 0.01 \\
\hline Syntax score & $27.7 \pm 9.0$ & $27.4 \pm 10.3$ & 0.77 \\
\hline Lesion calcification, $n(\%)$ & $85(75.9)$ & $719(55.2)$ & $<0.001$ \\
\hline Rotational atherectomy, $n(\%)$ & $26(23.0)$ & $111(8.5)$ & $<0.001$ \\
\hline IABP, $n(\%)$ & $11(9.7)$ & $141(10.8)$ & 0.87 \\
\hline IVUS, $n(\%)$ & $90(79.6)$ & $874(67.1)$ & 0.006 \\
\hline 2nd-generation DES & $72(62.1)$ & $679(51.4)$ & 0.03 \\
\hline MB stent diameter & $3.49 \pm 0.19$ & $3.44 \pm 0.24$ & 0.015 \\
\hline SB stent diameter & $3.15 \pm 0.43$ & $3.06 \pm 0.38$ & 0.23 \\
\hline $\mathrm{KBI}, n(\%)$ & $75(66.4)$ & $998(76.6)$ & 0.02 \\
\hline MB balloon size & $3.33 \pm 0.35$ & $3.32 \pm 0.36$ & 0.84 \\
\hline SB balloon size & $2.87 \pm 0.45$ & $2.87 \pm 0.39$ & 0.98 \\
\hline POT, $n(\%)$ & $81(71.7)$ & $866(66.5)$ & 0.30 \\
\hline POT balloon size, $\mathrm{mm}$ & $4.54 \pm 0.48$ & $4.32 \pm 0.43$ & $<0.001$ \\
\hline DSS & $33(29.2)$ & $426(32.7)$ & 0.47 \\
\hline Crush & $2(1.8)$ & $53(4.1)$ & \\
\hline Mini-crush & $9(8.0)$ & $160(12.3)$ & \\
\hline Culotte & $13(11.5)$ & $94(7.2)$ & \\
\hline TAP & $6(5.3)$ & $83(6.4)$ & \\
\hline T-stenting & $2(1.8)$ & $7(0.5)$ & \\
\hline $\mathrm{V}$-stenting & $1(0.9)$ & $27(2.1)$ & \\
\hline Kissing stenting & $0(0.0)$ & $2(0.2)$ & \\
\hline
\end{tabular}

Data are presented as percentages and absolute numbers or means \pm standard deviation, unless otherwise specified. HD, hemodialysis; 3VD, 3-vessel disease; IABP, intra-aortic balloon pumping; IVUS, intravascular ultrasound; DES, drug-eluting stents; MB, main branch; SB, side branch; KBI, kissing balloon inflation; POT, proximal optimization technique; SSS, single-stent strategy, TAP, T and protrusion.

ademic Research Consortium definitions [11]. Procedural success was defined as residual stenosis of $<30 \%$ with a thrombolysis in myocardial infarction flow of 3 at the final angiography. During follow-up, MI was defined as an increase in the Cr kinase-myocardial band mass to $>3$ times the normal upper limit with or without the presence of new pathological Q-waves on the electrocardiography [12].

\section{Statistical Analysis}

Values are reported as the mean \pm standard deviation. Differences in categorical variables between the 2 groups were analyzed using the $\chi^{2}$ test or Fisher exact tests as appropriate. Continuous variables were compared using the unpaired $t$ test or Wilcoxon rank-sum test where applicable. Time-to-event data were analyzed using the Kaplan-Meier method and log-rank test. Variables found to be associated in a univariate analysis $(p<0.2)$, and those judged to be of clinical importance based on previously published reports were eligible for inclusion in the multivariable model building process by the Cox regression analysis. The results were reported as the hazard ratio (HR) or adjusted HR with the associated $95 \%$ con- 
Table 3. Clinical outcomes during follow-up period

\begin{tabular}{|c|c|c|c|c|c|c|}
\hline & $\begin{array}{l}\text { HD } \\
(n=113)\end{array}$ & $\begin{array}{l}\text { Non-HD } \\
(n=1,303)\end{array}$ & $\begin{array}{l}\text { Unadjusted HR } \\
95 \% \text { CI }\end{array}$ & $p$ value & $\begin{array}{l}\text { Adjusted HR } \\
95 \% \mathrm{CI}\end{array}$ & $p$ value \\
\hline TLF & $70(61.9)$ & $308(23.6)$ & $3.77(2.90-4.91)$ & $<0.001$ & $2.62(1.87-3.66)$ & $<0.001$ \\
\hline Cardiac death & $38(33.6)$ & $79(6.1)$ & $8.17(5.52-12.1)$ & $<0.001$ & $4.39(2.64-7.31)$ & $<0.001$ \\
\hline TLR & $48(42.5)$ & $239(18.3)$ & $3.14(2.30-4.30)$ & $<0.001$ & $2.27(1.50-3.44)$ & $<0.001$ \\
\hline MI & $15(13.3)$ & $27(2.1)$ & $8.16(4.32-15.4)$ & $<0.001$ & $2.74(1.02-7.36)$ & 0.046 \\
\hline
\end{tabular}

HD, hemodialysis; HR, hazard ratio; CI, confidence interval; TLF, target lesion failure; TLR, target lesion revascularization; MI, myocardial infarction; ST, stent thrombosis.

Table 4. The predictors of TLF on Cox regression analysis

\begin{tabular}{|c|c|c|c|c|}
\hline & $\begin{array}{l}\text { Univariable HR } \\
(95 \% \mathrm{CI})\end{array}$ & $p$ value & $\begin{array}{l}\text { Adjusted HR } \\
(95 \% \mathrm{CI})\end{array}$ & $p$ value \\
\hline $\mathrm{HD}$ & $3.77(2.90-4.91)$ & $<0.001$ & $2.62(1.87-3.66)$ & $<0.001$ \\
\hline MB stent diameter & $0.37(0.25-0.55)$ & $<0.001$ & $0.40(0.26-0.62)$ & $<0.001$ \\
\hline True bifurcation & $1.77(1.42-2.20)$ & $<0.001$ & $1.46(1.14-1.86)$ & 0.002 \\
\hline $\mathrm{DM}$ & $1.47(1.20-1.79)$ & $<0.001$ & $1.32(1.06-1.63)$ & 0.013 \\
\hline $\mathrm{EF}$ & $0.98(0.97-0.99)$ & $<0.001$ & $0.99(0.98-0.99)$ & 0.003 \\
\hline POT & $0.64(0.52-0.78)$ & $<0.001$ & $0.72(0.57-0.91)$ & 0.006 \\
\hline Lesion calcification & $1.48(1.19-1.83)$ & $<0.001$ & $1.33(1.05-1.67)$ & 0.017 \\
\hline PAD & $1.79(1.40-2.28)$ & $<0.001$ & $1.29(0.97-1.71)$ & 0.077 \\
\hline Age & $0.99(0.98-0.99)$ & 0.009 & $0.99(0.98-1.00)$ & 0.052 \\
\hline DSS & $1.48(1.20-1.82)$ & $<0.001$ & $1.24(0.98-1.56)$ & 0.075 \\
\hline Female gender & $1.29(1.02-1.63)$ & 0.031 & $1.16(0.91-1.48)$ & 0.23 \\
\hline 2nd-generation DES & $0.76(0.61-0.93)$ & 0.009 & $0.91(0.72-1.15)$ & 0.43 \\
\hline DLP & $1.03(0.82-1.28)$ & 0.82 & & \\
\hline IVUS & $0.89(0.72-1.10)$ & 0.29 & & \\
\hline
\end{tabular}

TLF, target lesion failure; HR, hazard ratio; CI, confidence interval; $\mathrm{HD}$, hemodialysis; $\mathrm{MB}$, main branch; $\mathrm{DM}$, diabetes mellitus; EF, ejection fraction; POT, proximal optimization technique; PAD, peripheral artery disease; DSS, double-stent strategy; DES, drug-eluting stents; DLP, dyslipidemia; IVUS, intravascular ultrasound.

fidence interval (CI) and $p$ value. All $p$ values were two-sided, and $p<0.05$ was considered statistically significant. The analyses were performed using SPSS version 26.0 (IBM Corp., Armonk, NY, USA).

\section{Results}

Table 1 summarizes baseline clinical characteristics between the 2 groups. HD patients were more likely to be younger and have diabetes mellitus (DM), especially with insulin treatment, hypertension, dyslipidemia, CKD, peripheral artery disease, lower left ventricular ejection fraction (EF), and high EuroSCORE.
Table 2 summarizes baseline lesion and procedural characteristics between the 2 groups. Patients in the HD group had higher prevalence of 3 -vessel disease and calcified lesions, higher utilization of rotational atherectomy, intravascular ultrasound (IVUS). Kissing balloon inflation was more frequently performed, and a larger balloon size was used for POT.

\section{Clinical Outcomes}

The median follow-up period was 1,794 days (IQR: 1,151-2,270), and 3 years of clinical follow-up was available in $89.5 \%$ of the patients. Eighty-nine of $113 \mathrm{HD}$ patients were included from Japan. Clinical outcomes during the follow-up period are shown in Table 3. Kaplan-Meier 

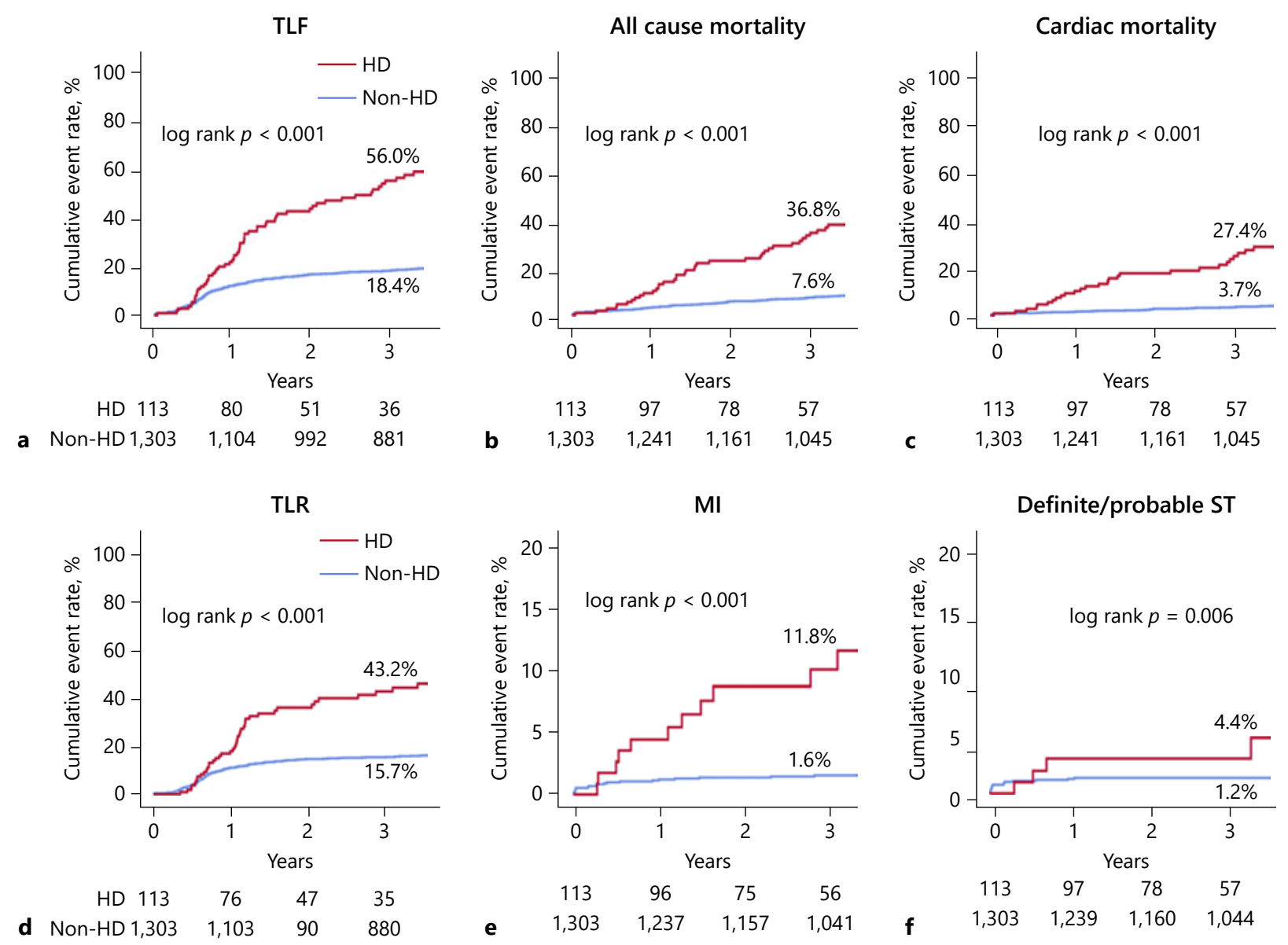

Fig. 2. Kaplan-Meier curve of TLF, cardiac mortality, TLR, MI, and definite/probable ST. a The rate of TLF at 3 years was significantly higher in the HD group than in the non-HD group $(56.0 \%$ in the HD group vs. $18.4 \%$ in the non-HD group, $\log$-rank $p<0.001)$. b All-cause mortality was significantly higher in the HD group than in the non-HD group (36.8\% in the HD group vs. $7.6 \%$ in the nonHD group, log-rank $p<0.001)$. c Cardiac mortality was significantly higher in the HD group than in the non-HD group $(27.4 \%$ in the HD group vs. $3.7 \%$ in the non-HD group, $\log -\operatorname{rank} p<0.001)$. d The rate of TLR was significantly higher in the HD group than in the non-HD group ( $43.2 \%$ in the HD group vs. $15.7 \%$ in the nonHD group, log-rank $p<0.001)$. e The rate of MI was comparable between the both groups $(11.8 \%$ in the HD group vs.1.6\% in the non-HD group, $\log$-rank $p<0.001)$. f The rate of definite/probable ST was comparable between both groups (4.4\% in the HD group vs. $1.2 \%$ in the non-HD group, log-rank $p=0.006)$. TLF, target lesion failure; TLR, target lesion revascularization; MI, myocardial infarction; ST, stent thrombosis; HD, hemodialysis. curves are shown in Figure 2. The rate of TLF was significantly higher in the HD group than that in the non-HD group (adjusted HR 2.67, 95\% CI: $1.90-3.75$, and $p<0.001$ ). All-cause mortality was significantly higher in the HD group than those in the non-HD group (adjusted HR 3.91, 95\% CI: $2.67-5.74$, and $p<0.001$ ). Cardiac mortality was significantly higher in the HD group than those in the nonHD group (adjusted HR 4.39, 95\% CI: 2.64-7.31, and $p<$ 0.001). Thirty-eight patients in HD group died 3 years after
PCI. The causes of death in HD patients are shown in Table 4. TLR rates was significantly higher in the HD group than those in the non-HD group (adjusted HR 2.27, 95\% CI: $1.50-3.44$, and $p<0.001$ ). The rate of MI was significantly higher in the HD group than those in the non-HD group (adjusted HR 2.74, 95\% CI: 1.02-7.36, and $p=0.046$ ). The rate of definite/probable ST was also significantly higher in the HD group than those in the non-HD group (adjusted HR 2.84, 95\% CI: 1.02-7.94, and $p=0.046$ ). 
Table 5. The predictors of TLF on Cox regression analysis in the cDES group

\begin{tabular}{|c|c|c|c|c|}
\hline & $\begin{array}{l}\text { Univariable HR } \\
(95 \% \mathrm{CI})\end{array}$ & $p$ value & $\begin{array}{l}\text { Adjusted HR } \\
(95 \% \mathrm{CI})\end{array}$ & $p$ value \\
\hline $\mathrm{HD}$ & $5.01(3.49-7.18)$ & $<0.001$ & $3.28(2.13-5.05)$ & $<0.001$ \\
\hline $\mathrm{DM}$ & $1.86(1.35-2.56)$ & $<0.001$ & $1.53(1.10-2.14)$ & 0.013 \\
\hline PAD & $2.10(1.47-2.98)$ & $<0.001$ & $1.12(0.72-1.74)$ & 0.48 \\
\hline Lesion calcification & $1.71(1.23-2.38)$ & 0.001 & $1.49(1.04-2.12)$ & 0.029 \\
\hline $\mathrm{EF}$ & $0.98(0.97-0.99)$ & 0.004 & $0.98(0.97-0.99)$ & 0.023 \\
\hline True bifurcation & $1.60(1.16-2.22)$ & 0.005 & $1.32(0.91-1.90)$ & 0.14 \\
\hline Age & $0.98(0.97-0.99)$ & 0.031 & $0.98(0.97-0.99)$ & 0.057 \\
\hline DSS & $1.42(1.02-1.97)$ & 0.036 & $1.25(0.87-1.81)$ & 0.23 \\
\hline Female gender & $1.41(0.99-2.02)$ & 0.057 & $1.48(1.02-2.15)$ & 0.039 \\
\hline POT & $0.77(0.53-1.12)$ & 0.17 & $0.84(0.57-1.24)$ & 0.38 \\
\hline MB stent diameter & $0.71(0.32-1.57)$ & 0.39 & & \\
\hline DLP & $1.08(0.77-1.53)$ & 0.65 & & \\
\hline IVUS & $0.99(0.70-1.43)$ & 0.99 & & \\
\hline
\end{tabular}

cDES, current generation drug-eluting stent; HD, hemodialysis; DM, diabetes mellitus; PAD, peripheral arterial disease; $\mathrm{EF}$, ejection fraction; POT, proximal optimization technique; MB, main branch; DLP, dyslipidemia; IVUS, intravascular ultrasound.

Table 6. Cause of death in HD group

\begin{tabular}{lc}
\hline & Number of deaths \\
\hline Sudden death & 10 \\
MI & 6 \\
Heart failure & 5 \\
Bleeding & 2 \\
Infection & 4 \\
Leg gangrene & 2 \\
Cancer & 2 \\
Stroke & 1 \\
Unknown & 6 \\
\hline
\end{tabular}

HD, hemodialysis; MI, myocardial infarction.

\section{Multivariable Analysis}

The results of the multivariable analysis with Cox regression analysis in overall population are shown in Table 5. The independent predictors of TLF were HD (adjusted HR 2.62, 95\% CI: 1.87-3.66, and $p<0.001$ ), main branch stent diameter (adjusted HR 0.40, 95\% CI: 0.260.62 , and $p<0.001$ ), true bifurcation lesions (adjusted HR 1.46, 95\% CI: 1.14-1.86, and $p=0.002$ ), DM (adjusted HR 1.32, 95\% CI: 1.06-1.63, and $p=0.013$ ), EF (adjusted HR 0.99, 95\% CI: 0.98-0.99, and $p=0.003$ ), POT (adjusted HR 0.72, 95\% CI: 0.57-0.91, and $p=0.006$ ), and lesion calcification (adjusted HR 1.33, 95\% CI: 1.05-1.67, and $p=0.017)$.

\section{Sub-Analysis of the Population Treated with cDES}

Baseline Clinical, Angiographic, and Procedural Characteristics

The baseline clinical characteristics of each subgroups are shown in online suppl. Table 1 (for all online suppl. material, see www.karger.com/doi/10.1159/000510731). The lesion and procedural characteristics are shown in online suppl. Table 2 .

\section{Clinical Outcomes}

The Kaplan-Meier curves of clinical event rates are shown in Figure 3. The rate of TLF, TLR, MI, and cardiac mortality at 3 years were significantly higher in the HD group than in the non-HD group. The rate of definite/ probable ST was comparable between the both groups.

\section{Multivariable Analysis}

The results of the multivariable analysis on the Cox regression analysis are shown in Table 6 . The independent predictors of TLF were HD (adjusted HR 3.28, 95\% CI: 2.13-5.05, and $p<0.001$ ), DM (adjusted HR 1.53, 95\% CI: $1.10-2.14$, and $p=0.013$ ), lesion calcification (adjusted HR 1.49 , 95\% CI: $1.04-2.12$, and $p=0.029$ ), EF (adjusted HR 0.98 , 95\% CI: $0.97-0.99$, and $p=0.023$ ), and female gender (adjusted HR 1.48, 95\% CI: 1.02-2.15, and $p=0.039$ ). 


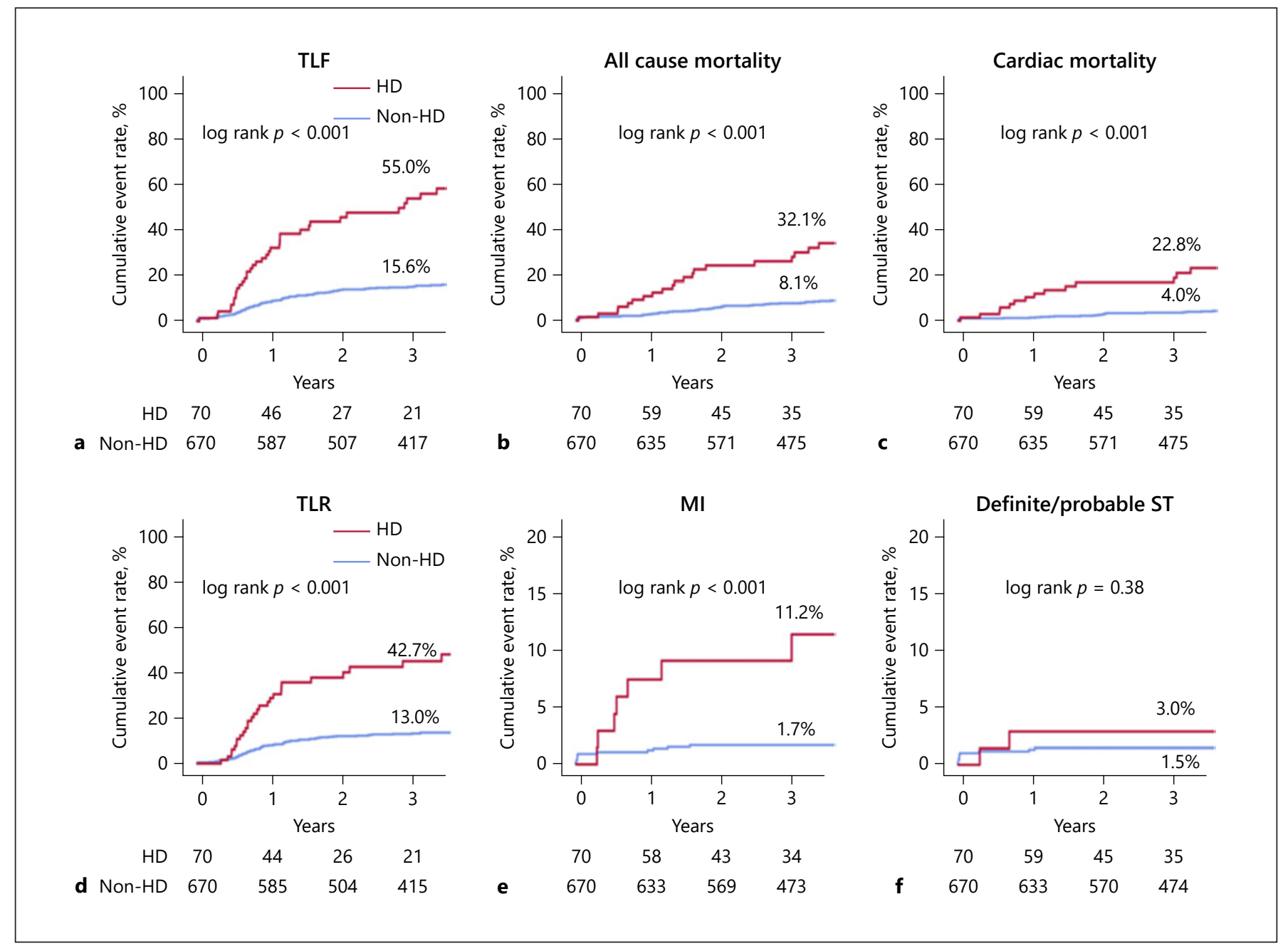

Fig. 3. Kaplan-Meier curve of TLF, cardiac mortality, TLR, MI, and definite/probable ST in cDES group. a The rate of TLF at 3 years was significantly higher in the HD group than in the non-HD group $(55.0 \%$ in the HD group vs. $15.6 \%$ in the non-HD group, $\log$-rank $p<0.001)$. b All-cause mortality was significantly higher in the HD group than in the non-HD group $(32.1 \%$ in the HD group vs. $8.1 \%$ in the non-HD group, $\log$-rank $p<0.001)$. c Cardiac mortality was significantly higher in the HD group than in the non-HD group $(22.8 \%$ in the HD group vs. $4.0 \%$ in the non-HD group, log-rank $p<0.001)$. d The rates of TLR was significantly

\section{Discussion}

The followings are the main findings of this study. (1) HD patients had more severe morbidity compared to non-HD patients. (2) HD was strongly associated with adverse events after PCI for ULMCA distal bifurcation lesions. (3) These findings were also consistent in the population treated with $\mathrm{cDES}$.

Clinical Outcomes of Dialysis with DES in Left Main Distal Bifurcation higher in the HD group than in the non-HD group $(42.7 \%$ in the HD group vs. $13.0 \%$ in the non-HD group, $\log$-rank $p<0.001)$. e The rate of MI was significantly higher in the HD group than in the non-HD group (11.2\% in the HD group vs. $1.7 \%$ in the nonHD group, log-rank $p<0.001)$. f The rate of definite/probable ST was comparable between the both groups $(3.0 \%$ in the HD group vs. $1.5 \%$ in the non-HD group, log-rank $p=0.38)$. TLF, target lesion failure; TLR, target lesion revascularization; MI, myocardial infarction; ST, stent thrombosis; HD, hemodialysis; cDES, current generation drug-eluting stent.

Dialysis is a treatment for the patients with end-stage of CKD [9]. Previous studies have demonstrated that patients with CKD have high prevalence of coronary artery disease $[13,14]$ and poorer overall outcomes even with successful revascularization [15]. The previous Japanese nationwide registry reported that dialysis patients had worse in-hospital outcomes after PCI compared with non-dialysis patients [16]. However, they do not refer to 
the long-term outcomes, being different from our study. Other previous studies also reported the unfavorable outcomes after PCI in HD patients [17-19]. Those results are consistent with our findings. But, none of those studies focus on ULMCA distal bifurcation lesions. Our present study is the first report about clinical outcomes after PCI with DES for ULMCA distal bifurcation lesions in HD patients. In the previous Japan multicenter postmarketing surveillance registry which was published in European Heart Journal, the authors reported the poorer clinical outcomes after PCI with SES in HD patients compared to non-HD patients [20]. The result is also consistent with our findings. But, the study also does not focus on ULMCA distal bifurcation lesions. Furthermore, the study does not provide the outcomes of PCI with cDES because the study population were treated with earlygeneration SES. We added the novel findings that the clinical outcomes in HD patients are very poor even if treated with cDES.

These worse clinical outcomes result from increased vascular calcification derived from secondary hyperparathyroidism and vascular endothelial dysfunction due to oxidative stress (OS) [21]. Numerous previous studies have reported that severe coronary calcification is associated with an unfavorable long-term clinical outcome after PCI $[22,23]$. Our group has also previously reported poor outcomes in HD patients with severely calcified lesions in the ULMCA lesions [24].

$\mathrm{CKD}$-mineral and bone disorder (CKD-MBD) is a well-known extra-renal complication in CKD patients. Abnormalities observed in CKD-MBD are the result of complex interactions among calcium, phosphate, magnesium, parathyroid hormone, and vitamin D [25]. CKDMBD causes severe cardiovascular calcification, morbidity, and mortality [26]. Previous study has suggested that arterial calcification is dependent on length of the morbidity of CKD [27]. Two recognized types of coronary artery classification are termed as intimal or superficial, and medial. Arterial calcification is a signature of advanced atherosclerosis, and the presence and the extent of calcification is strongly associated with poor prognosis [28]. Atherosclerotic calcification occurs mainly in the arterial intima [29]. On the other hand, medial calcification appears to be more strongly associated with CKD, hypercalcemia, hyperphosphatemia, abnormalities of parathyroid hormone, and duration of dialysis [30] and could potentially influence worse clinical outcomes in HD patients [31]. Previous report indicates the association between a severely calcified plaque and late luminal loss [32].
In addition, previous studies have reported that OS due to reactive oxygen species (ROS) are also strongly associated with adverse events after PCI [33]. The production of ROS is a strongly regulated process [34], and increased levels of ROS are associated with endothelial dysfunction, neointimal hyperplasia, vascular smooth muscle cell hypertrophy, and migration involved in the post-procedural remodeling process [33]. OS is present even in the early stages of CKD [35] and gradually increases along with renal impairment and becomes more severe in ESRD patients [36]. OS is further exacerbated by HD procedures because blood exposure to dialyzer membranes and dialyzate during dialysis procedures trigger activation of complement factors, platelets, and polymorphonuclear white blood cells, and subsequently ROS production, within minutes after initiation of dialysis sessions [37]. In addition, altered dietary restrictions and preferences in HD patients may also exaggerate the depletion of antioxidant defense mechanisms, such as low levels of vitamins $\mathrm{C}$ and $\mathrm{E}$, mainly because of dietary restrictions of vegetables and fruits, malnutrition, and loss of vitamins during HD procedure [38]. Due to these changes, it can be postulated that in HD patients, severe arterial calcification due to CKD-MBD and increased OS is strongly associated with worse clinical outcomes after PCI. HD patients have multiple high-grade negative factors in cardiovascular disease. The results of our substudy in population treated with cDES indicated that even cDES could be insufficient to overcome those negative factors present in HD patients. As previously reported, for ULMCA bifurcation lesions, SSS is favorable strategy with better clinical outcomes when compared with those in DSS. However, even similar rate of SSS in the both groups in our study ( $>60 \%)$, TLR rate was significantly higher in the HD group. Our cox regression multivariate analysis demonstrated that HD may be independently associated with poor clinical outcomes even after successful ULMCA bifurcation PCI. Moreover, despite rotational atherectomy and IVUS were more frequently performed in the HD group, which are associated with more favorable clinical outcomes $[39,40]$. These results also indicate worse clinical outcome in HD patients compared to non-HD patients.

In summary, $\mathrm{HD}$ patients can be one of the last challenges left in our frontier of PCI for ULMCA distal bifurcation lesions. HD patients who have ULMCA disease still remain a high-risk group for PCI. We consider that the treatment strategy for severely calcified lesions is very important in the treatment of HD patient. Previous studies reported that lesion preparation before stent deploy- 
ment by rotational atherectomy played an important role to obtain a good result in the acute phase [41, 42]. Even though HD patients survive the procedure and initial hospitalization after PCI, they remain at high risk for adverse events. Also in the present study, death occurred much more frequently in HD patients than in non-HD patients. Although we can overcome the calcified lesion during PCI with some technologies such as scoring balloon, rotational atherectomy, and orbital atherectomy, they could be insufficient to guarantee an acceptable long-term clinical outcomes. Further efforts should concentrate on identifying the factors associated with adverse events after PCI in HD patients to improve long-term outcomes. Furthermore, a novel strategy to improve the long-term outcomes of PCI for calcified lesions in HD patients may be necessary. Further studies are required to solve the problems involving HD.

\section{Limitations}

First, this was a nonrandomized, retrospective, observational study. The data could have resulted in selection bias. Several baseline characteristics were significantly different between the groups, and the decision-making in PCI strategies was made at the operator's discretion. Second, although IVUS is strongly recommended for PCI of ULMCA, IVUS was not used in all cases. Third, the duration and indication for HD treatment may impact on their clinical outcome; however, in this study, they could not be analyzed sufficiently. Fourth, angiographic followup was performed according to each institution's strategy and each operator's discretion, which may affect TLR rate. Finally, we did not clarify differences in HD patient backgrounds by country.

\section{Conclusion}

HD was strongly associated with adverse events after PCI for ULMCA distal bifurcation lesions. Furthermore, the clinical outcomes were poor even if treated with cDES.

\section{Statement of Ethics}

The authors have no ethical conflicts to disclose.

\section{Conflict of Interest Statement}

The authors have no conflicts of interest regarding the content of this article.

\section{Funding Sources}

No specific financial support was obtained for the preparation of this article.

\section{References}

1 Moses JW, Leon MB, Popma JJ, Fitzgerald PJ, Holmes DR, O'Shaughnessy C, et al. Sirolimus-eluting stents versus standard stents in patients with stenosis in a native coronary artery. N Engl J Med. 2003 Oct 2;349(14):131523.

2 Mohr FW, Morice MC, Kappetein AP, Feldman TE, Ståhle E, Colombo A, et al. Coronary artery bypass graft surgery versus percutaneous coronary intervention in patients with three-vessel disease and left main coronary disease: 5 -year follow-up of the randomised, clinical SYNTAX trial. Lancet. 2013 Feb 23; 381(9867):629-38.

3 Stone GW, Sabik JF, Serruys PW, Simonton CA, Généreux P, Puskas J, et al. Everolimuseluting stents or bypass surgery for left main coronary artery disease. N Engl J Med. 2016 Dec 8;375(23):2223-35.

4 Waksman R, Barbash IM, Dvir D, Torguson R, Ben-Dor I, Maluenda G, et al. Safety and efficacy of the XIENCE V everolimus-eluting stent compared to first-generation drug- eluting stents in contemporary clinical practice. Am J Cardiol. 2012 May 1;109(9):128894.

5 Sarnak MJ, Levey AS, Schoolwerth AC, Coresh J, Culleton B, Hamm LL, et al. Kidney disease as a risk factor for development of cardiovascular disease: a statement from the American Heart Association Councils on kidney in cardiovascular disease, high blood pressure research, clinical cardiology, and epidemiology and prevention. Circulation. 2003 Oct 28;108(17):2154-69.

6 Pan Y, Qiu Q, Chen F, Li X, Yu X, Luo Y, et al. Impact of chronic kidney disease on patients with unprotected left main coronary artery disease treated with coronary artery bypass grafting or drug-eluting stents. Coron Artery Dis. 2016 Nov;27(7):535-42.

7 Ota T, Umeda H, Yokota S, Miyata S, Takamura A, Sugino S, et al. Relationship between severity of renal impairment and 2-year outcomes after sirolimus-eluting stent implantation. Am Heart J. 2009 Jul;158(1):92-8.
8 Takeuchi I, Moriguchi M, Imaki R, Fukaya H, Shinagawa H, Shimohama T, et al. Hemodialysis is an independent predictor of coronary in-stent restenosis after paclitaxel eluting stent implantation. Intern Med. 2010;49(22): 2379-84.

9 Chapter 1: definition and classification of CKD. Kidney Int Suppl. 2013 Jan;3(1):19-62.

10 Medina A, Suárez de Lezo J. Percutaneous coronary intervention in bifurcation lesions. Does classification aid treatment selection? Rev Esp Cardiol. 2009 Jun;62(6):595-8.

11 Cutlip DE, Windecker S, Mehran R, Boam A, Cohen DJ, van Es GA, et al. Clinical end points in coronary stent trials: a case for standardized definitions. Circulation. 2007 May 1; 115(17):2344-51.

12 Chen SL, Xu B, Han YL, Sheiban I, Zhang JJ, Ye F, et al. Clinical outcome after DK crush versus culotte stenting of distal left main bifurcation lesions: the 3-year follow-up results of the DKCRUSH-III Study. JACC Cardiovasc Interv. 2015 Aug 24;8(10):1335-42. 
13 Lysaght MJ. Maintenance dialysis population dynamics: current trends and long-term implications. J Am Soc Nephrol. 2002 Jan; 13(Suppl 1):S37-40.

14 Tsai TT, Messenger JC, Brennan JM, Patel UD, Dai D, Piana RN, et al. Safety and efficacy of drug-eluting stents in older patients with chronic kidney disease: a report from the linked CathPCI registry-CMS claims database. J Am Coll Cardiol. 2011 Oct 25;58(18): 1859-69.

15 Naidu SS, Selzer F, Jacobs A, Faxon D, Marks DS, Johnston J, et al. Renal insufficiency is an independent predictor of mortality after percutaneous coronary intervention. Am J Cardiol. 2003 Nov 15;92(10):1160-4.

16 Numasawa $\mathrm{Y}$, Inohara T, Ishii $\mathrm{H}$, Yamaji $\mathrm{K}$, Hirano K, Kohsaka S, et al. An overview of percutaneous coronary intervention in dialysis patients: insights from a Japanese nationwide registry. Catheter Cardiovasc Interv. 2019 Jul 1;94(1):E1-8.

17 Shroff GR, Solid CA, Herzog CA. Response to letter regarding article, "Long-term survival and repeat coronary revascularization in dialysis patients after surgical and percutaneous coronary revascularization with drug-eluting and bare metal stents in the United States". Circulation. 2013;128(20):e407-69.

18 Li S, Ye D, Chen G, Xu W. Meta-analysis of comparison of drug-eluting stents and baremetal stents in patients on dialysis. Am J Cardiol. 2017;119(8):1186-92.

19 Chen ML, Wu JL, Chen MY, Hsieh TC. Longterm clinical outcome of drug-eluting vs. bare-metal stent implantation after percutaneous coronary intervention in end-stage renal disease patients on hemodialysis- Nationwide Cohort Study in Taiwan. Circ J. 2019 May 24;83(6):1239-46.

20 Otsuka Y, Ishiwata S, Inada T, Kanno H, Kyo E, Hayashi Y, et al. Comparison of haemodialysis patients and non-haemodialysis patients with respect to clinical characteristics and 3-year clinical outcomes after sirolimuseluting stent implantation: insights from the Japan multi-centre post-marketing surveillance registry. Eur Heart J. 2011 Apr;32(7): 829-37.

21 Stenvinkel P, Pecoits-Filho R, Lindholm B. Coronary artery disease in end-stage renal disease: no longer a simple plumbing problem. J Am Soc Nephrol. 2003 Jul;14(7):192739.
22 Moussa I, Di Mario C, Moses J, Reimers B, Di Francesco L, Martini G, et al. Coronary stenting after rotational atherectomy in calcified and complex lesions. Angiographic and clinical follow-up results. Circulation. 1997 Jul 1; 96(1):128-36.

23 Kim MC, Ahn Y, Sim DS, Hong YJ, Kim JH, Jeong $\mathrm{MH}$, et al. Impact of calcified bifurcation lesions in patients undergoing percutaneous coronary intervention using drugeluting stents: results from the COronary BIfurcation Stent (COBIS) II registry. EuroIntervention. 2017 Jun 20;13(3):338-44.

24 Yabushita H, Takagi K, Tahara S, Fujino Y, Warisawa T, Kawamoto $H$, et al. Impact of rotational atherectomy on heavily calcified, unprotected left main disease. Circ J. 2014; 78(8):1867-72.

25 Isakova T, Wahl P, Vargas GS, Gutiérrez OM, Scialla J, Xie H, et al. Fibroblast growth factor 23 is elevated before parathyroid hormone and phosphate in chronic kidney disease. Kidney Int. 2011 Jun;79(12):1370-8.

26 Reiss AB, Miyawaki N, Moon J, Kasselman LJ, Voloshyna I, D’Avino R Jr, et al. CKD, arterial calcification, atherosclerosis and bone health: inter-relationships and controversies. Atherosclerosis. 2018 Nov;278:49-59.

27 Karwowski W, Naumnik B, Szczepański M, Myśliwiec M. The mechanism of vascular calcification: a systematic review. Med Sci Monit. 2012 Jan;18(1):Ra1-11.

28 Detrano R, Guerci AD, Carr JJ, Bild DE, Burke G, Folsom AR, et al. Coronary calcium as a predictor of coronary events in four racial or ethnic groups. N Engl J Med. 2008 Mar 27; 358(13):1336-45.

29 Demer LL, Tintut Y. Vascular calcification: pathobiology of a multifaceted disease. Circulation. 2008 Jun 3;117(22):2938-48.

30 Abedin M, Tintut Y, Demer LL. Vascular calcification: mechanisms and clinical ramifications. Arterioscler Thromb Vasc Biol. 2004 Jul;24(7):1161-70.

31 Chen Z, Qureshi AR, Ripsweden J, Wennberg L, Heimburger O, Lindholm B, et al. Vertebral bone density associates with coronary artery calcification and is an independent predictor of poor outcome in end-stage renal disease patients. Bone. 2016 Nov;92:50-7.

32 Fujino Y, Attizzani GF, Tahara S, Takagi K, Bezerra HG, Nakamura S, et al. Frequencydomain optical coherence tomography assessment of unfavorable kissing-balloon result in unprotected left main intervention. JACC Cardiovasc Interv. 2013 Dec;6(12): $1324-5$.
33 Gallo G, Pierelli G, Forte M, Coluccia R, Volpe M, Rubattu S. Role of oxidative stress in the process of vascular remodeling following coronary revascularization. Int J Cardiol. 2018 Oct 1;268:27-33.

34 Touyz RM, Briones AM. Reactive oxygen species and vascular biology: implications in human hypertension. Hypertens Res. 2011 Jan; 34(1):5-14.

35 Zhu C, Mertens PR. IgA nephropathy and oxidative stress: news on clinically evaluated biomarkers hits the stage. Int Urol Nephrol. 2012 Aug;44(4):1277-80.

36 Boudouris G, Verginadis II, Simos YV, Zouridakis A, Ragos V, Karkabounas SC, et al. Oxidative stress in patients treated with continuous ambulatory peritoneal dialysis (CAPD) and the significant role of vitamin $\mathrm{C}$ and $\mathrm{E}$ supplementation. Int Urol Nephrol. 2013 Aug;45(4):1137-44.

37 Liakopoulos V, Roumeliotis S, Gorny X, Dounousi E, Mertens PR. Oxidative stress in hemodialysis patients: a review of the literature. Oxid Med Cell Longev. 2017;2017:3081856.

38 Canaud B, Cristol J, Morena M, Leray-Moragues $\mathrm{H}$, Bosc J, Vaussenat F. Imbalance of oxidants and antioxidants in haemodialysis patients. Blood Purif. 1999;17(2-3):99-106.

39 Casella G, Klauss V, Ottani F, Siebert U, Sangiorgio $P$, Bracchetti $D$. Impact of intravascular ultrasound-guided stenting on long-term clinical outcome: a meta-analysis of available studies comparing intravascular ultrasoundguided and angiographically guided stenting. Catheter Cardiovasc Interv. 2003 Jul;59(3): $314-21$.

40 Fuku Y, Kadota K, Toyofuku M, Morimoto T, Ohya M, Higami $\mathrm{H}$, et al. Long-term outcomes of drug-eluting stent implantation after rotational atherectomy for left main coronary artery bifurcation lesions. Am J Cardiol. 2019 Jun 1;123(11):1796-805.

41 Warth DC, Leon MB, O'Neill W, Zacca N, Polissar NL, Buchbinder M. Rotational atherectomy multicenter registry: acute results, complications and 6-month angiographic follow-up in 709 patients. J Am Coll Cardiol. 1994 Sep;24(3):641-8.

42 Reisman M, Harms V, Whitlow P, Feldman T, Fortuna R, Buchbinder M. Comparison of early and recent results with rotational atherectomy. J Am Coll Cardiol. 1997 Feb;29(2): $353-7$. 